\title{
VAPORIZATION OF MERCURY FROM MOLTEN LEAD DROPLETS DOPED WITH MERCURY: Pb/Hg SOURCE TERM EXPERIMENT FOR THE APT/SILC TARGET
}

\author{
Narinder K. Tutu and George A. Greene
}

September 1994

Department of Advanced Technology

BROOKHAVEN NATIONAL LABORATORY

ASSOCIATED UNIVERSITIES, INC.

UPTON, LONG ISLAND, NEW YORK 11973

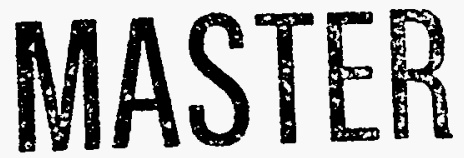

UNDER CONTRACT NO DE-AC02-76CH00016 WITH THE UNITED STATES DEPARTMENT OF ENERGY 


\section{DISCLAIMER}

This report was prepared as an account of work sponsored by an agency of the United States Government. Neither the United States Government nor any agency thereof, nor any of their employees, nor any of their contractors, subcontractors, or their employees, makes any warranty, express or implied, or assumes any legal liability or responsibility for the accuracy, completeness, or usefulness of any information, apparatus, product, or process disclosed, or represents that its use would not infringe privately owned rights. Reference herein to any specific commercial product, process, or service by trade name, trademark, manufacturer, or otherwise, does not necessarily constitute or imply its endorsement, recommendation, or favoring by the United States Government or any agency, contractor or subcontractor thereof. The views and opinions of authors expressed herein do not necessarily state or reflect those of the United States Government or any agency, contractor or subcontractor thereof.

Printed in the United States of America Available from

National Technical Information Service

U.S. Department of Commerce

5285 Port Royal Road

Springfield, VA 22161

NTIS price codes:

Printed Copy: A03; Microfiche Copy: A01 


\section{DISCLAIMER}

Portions of this document may be illegible in electronic image products. Images are produced from the best available original document. 


\begin{abstract}
Experiments were performed to measure the fraction of mercury inventory released when droplets of molten lead, doped with a known concentration of mercury, fall through a controlled environment. The temperature of molten droplets ranged from $335^{\circ} \mathrm{C}$ to $346^{\circ} \mathrm{C}$, and the concentration of mercury in the droplets ranged from 0.2 mass $\%$ to 1.0 mass $\%$. The environment consisted of an air stream, at a temperature nominally equal to the melt temperature, and moving vertically upwards at a velocity of $10 \mathrm{~cm} / \mathrm{s}$. Direct observations and chemical analysis showed that no mercury was released from the molten droplets. Based upon the experimental results, it is concluded that no mercury vapor is likely to be released from the potentially molten source rod material in the APT-SILC Neutron Source Array to the confinement atmosphere during a postulated Large Break Loss Of Coolant Accident scenario leading to the melting of a fraction of the source rods.
\end{abstract}





\section{EXECUTIVE SUMMARY}

It is necessary to investigate the consequences of certain postulated design-basis and beyonddesign-basis accident scenarios in order to quantify the environmental impact of the proposed Accelerator Production of Tritium (APT) Spallation Induced Lithium Conversion (SILC) facility. Transient-heattransfer calculations to predict the thermal response of the APT-SILC source to a postulated beyonddesign-basis accident scenario show that a maximum of $27 \%$ of the lead inventory $(6558 \mathrm{~kg})$ in the source rods may melt owing to the decay heat. The postulated accident scenario assumes a Large Break Loss Of Coolant Accident (LBLOCA) which is immediately followed by a successful trip of the proton beam, tripping of the Source Primary Coolant System (SPCS) pumps, and the activation of the Source Basin Flood System. The accident scenario assumes the simultaneous failure of all active cooling systems in order to be conservative. Furthermore, it is postulated that natural circulation is not established in the unbroken loop (the second primary coolant system loop) following the LOCA for this beyond-design-basis scenario.

The melting of source rods is predicted to occur over a period of seven hours. As the lead rods melt, the molten material would fall into the $\mathrm{D}_{2} \mathrm{O}$-filled bottom header of the source, quench rapidly, and remain in a coolable state. Thus, during this brief period while the molten material drops to the waterfilled bottom header, radionuclides in the molten lead can be released to the steam environment in the pressure tubes. Many radionuclides are produced in the lead source rods during operation. The mercury isotopes are the dominant nongaseous radionuclides produced. Although a significant quantity of thallium is produced, it does not contribute significantly to the confinement source term owing to its low volatility. Consequently, the fraction of the mercury inventory that would be vaporized needs to be predicted. With this objective, experiments were performed to measure the fraction of mercury inventory released when droplets of molten lead, doped with a known concentration of mercury, fall through a controlled environment. The temperature of molten droplets ranged from $335^{\circ} \mathrm{C}$ to $346^{\circ} \mathrm{C}$, and the concentration of mercury in the droplets ranged from 0.2 mass $\%$ to 1.0 mass $\%$.

The test section consists of a glass-lined 50.8-mm-diameter stainless-steel pipe that is 1 -m high. The small opening between the melt vessel and the test section is blocked by a conical stainless-steel plunger. A known mass of lead is placed in the melt vessel, and the test section and the melt vessel are then heated. Hot air is circulated through the test section at a known flow rate and temperature. Upon attainment of steady state, a given mass of mercury is added to the molten lead in the melt vessel. The experiment is initiated by moving the plunger and allowing molten droplets to fall through the test section at a controlled rate. During the experiment the hot air exiting the top of the test section is passed through three condensers and a water pool before being discharged to the atmosphere. Thus any mercury released from the molten droplets is carried off by the hot air and trapped in the condensers.

Direct observation of condensers showed no mercury to be present at the end of every test. Chemical analysis of the solidified material collected at the bottom of the test section by the Inductively Coupled Plasma Atomic Emission Spectrometry confirmed the conclusion that no mercury was released from molten droplets during the experiments. Based upon the experimental results, it is concluded that no mercury vapor will be released from the molten source rod material to the confinement atmosphere during a postulated LBLOCA scenario leading to the melting of a fraction of the source rods. 
, 


\section{TABLE OF CONTENTS}

ABSTRACT $\ldots \ldots \ldots \ldots \ldots \ldots \ldots \ldots \ldots \ldots \ldots \ldots \ldots \ldots \ldots \ldots \ldots \ldots$ iii

EXECUTIVE SUMMARY $\ldots \ldots \ldots \ldots \ldots \ldots \ldots \ldots \ldots \ldots \ldots \ldots$

LIST OF FIGURES $\ldots \ldots \ldots \ldots \ldots \ldots \ldots \ldots \ldots \ldots \ldots \ldots \ldots \ldots \ldots \ldots \ldots$

IIST OF TABLES $\ldots \ldots \ldots \ldots \ldots \ldots \ldots \ldots \ldots \ldots \ldots \ldots \ldots \ldots \ldots \ldots \ldots \ldots$

ACKNOWLEDGEMENTS $\ldots \ldots \ldots \ldots \ldots \ldots \ldots \ldots \ldots \ldots \ldots \ldots \ldots \ldots$ xiii

1. INTRODUCTION $\ldots \ldots \ldots \ldots \ldots \ldots \ldots \ldots \ldots \ldots \ldots \ldots \ldots \ldots \ldots \ldots \ldots \ldots$

$1.1 \quad$ Background . . . . . . . . . . . . . . . . . . . . . 1

1.2 Thermal Response of the APT-SILC Target to a Postulated Large-Break LOCA .......................... 1

1.3 Purpose and Scope of the Experiments $\ldots \ldots \ldots \ldots \ldots \ldots \ldots \ldots \ldots$

2. EXPERIMENTAL APPARATUS AND METHOD $\ldots \ldots \ldots \ldots \ldots \ldots \ldots \ldots$

$2.1 \quad$ Experimental Apparatus . . . . . . . . . . . . . . . .

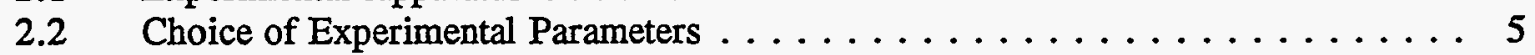

$2.3 \quad$ Experimental Procedure $\ldots \ldots \ldots \ldots \ldots \ldots \ldots \ldots \ldots$

3. RESULTS AND DISCUSSION $\ldots \ldots \ldots \ldots \ldots \ldots \ldots \ldots \ldots \ldots$

4. CONCLUDING REMARKS $\ldots \ldots \ldots \ldots \ldots \ldots \ldots \ldots \ldots \ldots \ldots \ldots \ldots \ldots \ldots$

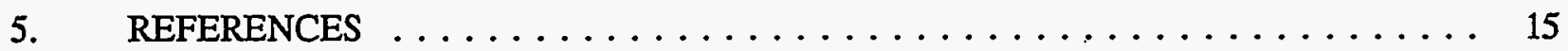


, 


\section{LIST OF FIGURES}

Figure

Page

1. Thermal response of the APT-SILC source to a LBLOCA with immediate beam trip and no natural circulation in the unbroken loop. Basin heat exchanger is assumed

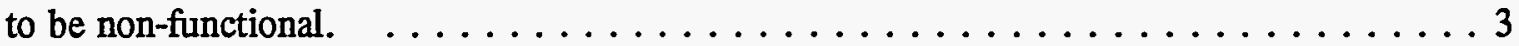

2. A schematic of the experimental apparatus. $\ldots \ldots \ldots \ldots \ldots \ldots \ldots \ldots$ 
, 


\section{LIST OF TABLES}

\section{Table}

Page

1. Experimental parameters and the results $\ldots \ldots \ldots \ldots \ldots \ldots \ldots \ldots$

2. Mercury concentration measurements in the solidified samples from the Inductively Coupled Plasma Atomic Emission Spectrometry (ICP-AES). 
, 


\section{ACKNOWLEDGEMENTS}

Thanks are due to Mr. Rupert Galea and Mr. Yury Faktorovich for the mechanical design of the test section and melt vessel. Mr. C. Eric Schwarz and Mr. John R. Klages fabricated the experimental apparatus and participated in the performance of experiments. Special thanks are due to Dr. Mark Fuhrmann and Ms. Huan Zhou for chemical analysis of the samples to measure the concentration of mercury.

xiii 


\section{INTRODUCTION}

\subsection{Background}

A preconceptual design for the Spallation Induced Lithium Conversion (SILC) target for the Accelerator Production of Tritium (APT) is given in Reference [1]. The neutron-producing source region of the APT-SILC facility consists of an array of aluminum-clad lead rods held inside aluminum pressure tubes. During normal operation, neutrons are produced within the source by spallation reactions induced by the incident proton beam. The energy deposited in the lead source rods is removed by circulation of heavy water through the pressure tubes. Many radionuclides are produced in the lead source rods during operation as a result of the intranuclear cascade reactions. The mercury isotopes are the dominant nongaseous radionuclides produced. Although a significant quantity of thallium is produced, it does not contribute significantly to the confinement source term owing to its low volatility.

As part of the Programmatic Environmental Impact Statement (PEIS) submittal for the APT, a Beyond Design Basis Event (BDBE) accident analysis has been performed for the SILC target system in order to develop a bounding estimate for the release of spallation products from a damaged spallation target. Details of the calculations to predict the thermal response of the APT-SILC target to this postulated Large Break Loss of Coolant Accident (LBLOCA) will not be given here. However, the results of these calculations are briefly summarized below to provide a rationale for the present experiments. The terminology used in the following section is consistent with Reference [1], which describes the Rev. 0 of the APT-SILC preconceptual design. In the revised version (Rev.1) of the APTSILC preconceptual design report, the terminology has been modified.

\subsection{Thermal Response of the APT-SILC Target to a Postulated Large-Break LOCA}

Transient-heat-transfer calculations have been performed for the following conservative accident scenario. The large-break LOCA is immediately followed by a successful trip of the proton beam, tripping of the Source Primary Coolant System (SPCS) pumps, and the activation of the Source Basin Flood System. The accident scenario assumes the simultaneous failure of all active cooling systems in order to be conservative. These include, the Source Residual Primary Cooling System (SRPCS), the Blanket Primary Cooling System (BPCS), and the Source Basin Cooling System (SBCS). In addition, it was assumed that passive cooling would fail as well, i.e.., natural circulation would not be established in the unbroken loop of the SPCS although this is the design basis for the Source Primary Cooling System. The probability of this accident will place it into the residual risk category. Although this accident is of such low frequency as to be of dubious value in estimating on-site and off-site radiation doses (residual risk events are considered to be of such low probability that their risk is acceptable), it may be useful to consider such events while the designs of the cooling systems and the confinement continue to evolve, in order to further enhance the passive safety of the facility by uncovering any relative vulnerabilities and allowing the design to accommodate and/or eliminate them.

A preliminary source temperature history for this case is shown in Figure 1 . Assuming that the beam and pumps are tripped at time zero, the pump coast-down period would end at 45 seconds. Since the decay heat during this time would be about $1 \%$ of the operating power, the source actually cools to

$62^{\circ} \mathrm{C}$ during the pump coast down period. From 45 seconds to 90 seconds, the time at which the basin is completely flooded, it is assumed that the source heats up adiabatically. At 90 seconds, the average temperature of the spallation source is calculated to be $65.5^{\circ} \mathrm{C}$. 
Since the failure of all active systems is assumed, the water in the basin is assumed to heat up adiabatically due to heat transfer from the source pressure tubes. Transient heat transfer calculations show that the source reaches the saturation temperature of $101.42^{\circ} \mathrm{C}$ at 22.8 hours. From this time onwards, the heavy water within the source would boil off. At approximately 31 hours into the accident, the water inventory from the unbroken loop drains as the upper header is uncovered. This $\mathrm{D}_{2} \mathrm{O}$ inventory (at $62^{\circ} \mathrm{C}$ ) would sweep through the source pressure tubes and the upper header rapidly, displacing the saturated water with cold water from the unbroken loop. This would result in a rapid cool-down of the source pressure tubes, but only for a very short time. The source rods and water would quickly reheat to saturation in less than 30 minutes.

Calculations show that at 37.2 hours, the basin water would have reached $100^{\circ} \mathrm{C}$. Therefore, from this time forward, heat would be transferred from the pressure tubes to the basin water via boiling heat transfer. At 43.6 hours into the accident, the $\mathrm{D}_{2} \mathrm{O}$ inventory in the upper header of the source would have been boiled off and the source rods would begin to be uncovered. At 48.4 hours the source would have boiled dry. Until this time, the temperature of the spallation source had not exceeded the $\mathrm{D}_{2} \mathrm{O}$ saturation temperature. From this time onwards, the source rods heat up. At 50.4 hours into the accident, while the average source temperature has only reached $218.7^{\circ} \mathrm{C}$, the centerline temperature in the pressure tubes has reached the melting point of lead $\left(327.4^{\circ} \mathrm{C}\right)$. At this time, $\mathrm{Pb}$ in the central regions of the pressure tubes will begin to melt. When the average source temperature reaches $302.9^{\circ} \mathrm{C}$, heat transfer from the source rods to the pressure tubes would be equal to the decay heat, assuming that the source had operated continuously for one year prior to the accident. This occurs at 57.3 hours. Since the decay heat would be continuously decreasing with time, from this time onwards the source rods would cool. By this time, $26.8 \%$ of the lead $(6558 \mathrm{~kg})$ in the source rods would have melted, relocated to the bottom header, frozen, and quenched. Since beyond this time the average source temperature would continuously decrease, the system would be coolable.

During the melting period of approximately seven hours, the lead is calculated to heat only to its melting point of $327.4^{\circ} \mathrm{C}$. The molten lead from the damaged spallation rods would remain molten only as long as it took to fall under gravity into the water in the inlet header. This would be on the order of one second (calculated to be $0.64 \mathrm{sec}$ for a 2 meter fall). Over this period of seven hours of melting, the total mass of $6558 \mathrm{~kg}$ of lead calculated to melt would require the vaporization of $162.5 \mathrm{~kg}$ of water to freeze and quench this mass of debris in the inlet header. There is more than $2000 \mathrm{~kg}$ of $\mathrm{D}_{2} \mathrm{O}$ in the lower header, an order of magnitude more water than would be necessary to freeze and quench all of the lead debris. Since the cross-sectional area for upflow in all the source pressure tubes is $0.36 \mathrm{~m}^{2}$, this results in an average steam velocity through all the spallation source pressure tubes of approximately 3 $\mathrm{cm} / \mathrm{s}$.

The driving force for the volatilization and transport of radionuclides from the molten lead would be minimal at best. Since the lead relocation process (free fall) will limit the time during which the lead will be molten to the order of seconds, rate-limiting processes such as mass diffusion in the molten lead will play a dominant role in limiting the vaporization release of radionuclides such as $\mathrm{Hg}$. Those radionuclides that would be released from the melt would be carried upwards through the densely packed pressure tubes by the steam flow from the lower header of $3 \mathrm{~cm} / \mathrm{s}$, through the upper header and the SPCS piping, through the pump and heat exchanger, and finally out the break location and into the confinement air space.

\subsection{Purpose and Scope of the Experiments}

In order to quantify the environmental impact of the proposed APT-SILC facility, it is necessary 


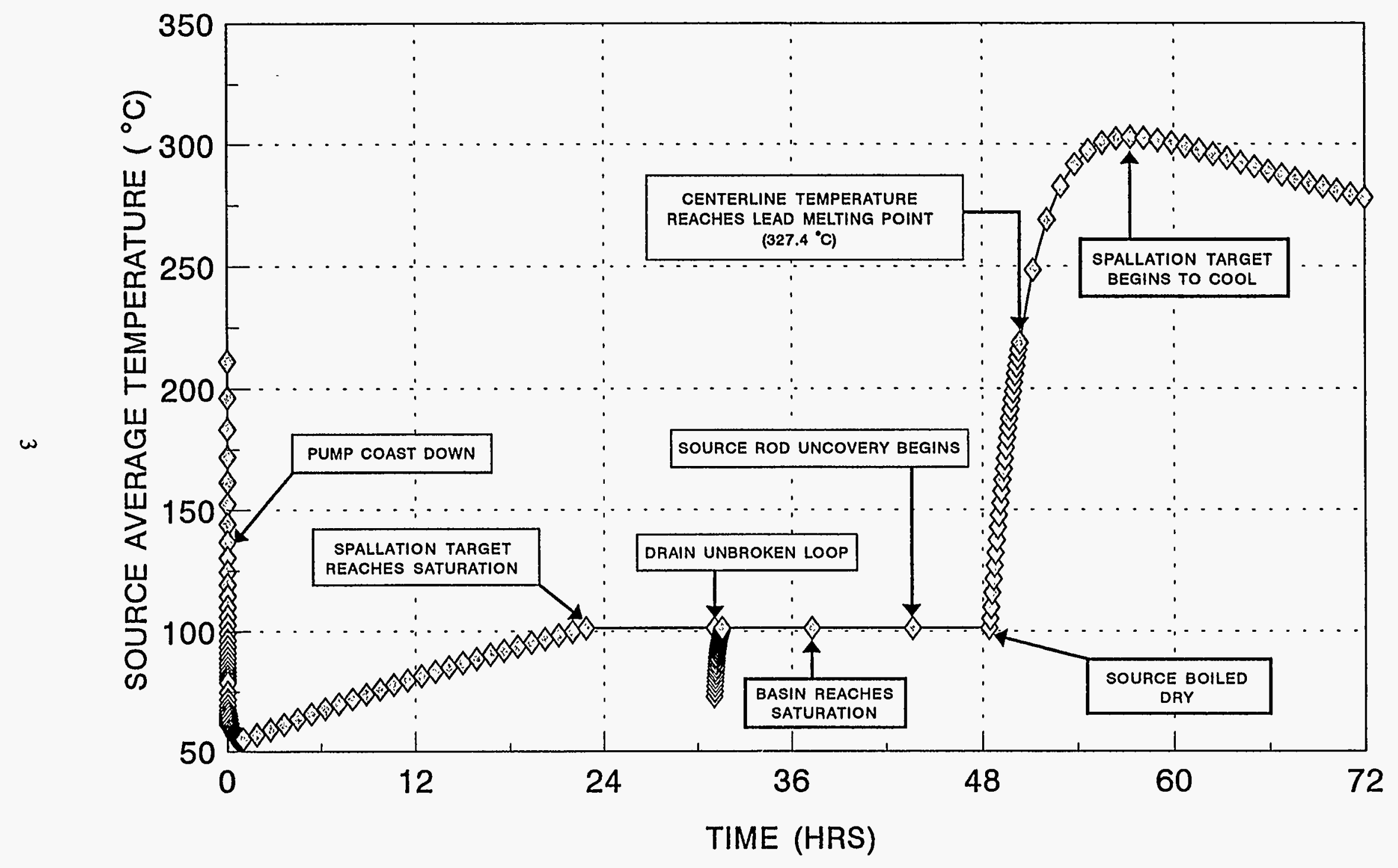

Figure 1. Thermal response of the APT-SILC source to a LBLOCA with immediate beam trip and no natural circulation in the unbroken loop. The basin heat exchanger is assumed to be non-functional. 
to know the rate of volatilization of elemental mercury from molten lead. Consistent with the LBLOCA accident scenario described above, the objective of these tests is to measure the fraction of mercury inventory released when droplets of molten lead, doped with a known concentration of mercury, fall through a controlled environment. The experimental parameters that were varied are the initial concentration of mercury in the lead, and the melt temperature.

The experimental apparatus and method are described in the next chapter, and the results are discussed in Chapter 3. Finally, some concluding remarks are presented in Chapter 4. 


\section{EXPERIMENTAL APPARATUS AND METHOD}

\subsection{Experimental Apparatus}

A schematic of the experimental apparatus is shown in Figure 2. The test section consists of a glass-lined 50.8-mm-diameter stainless-steel pipe that is 1-m high. A stainless-steel melt vessel of identical internal diameter is bolted on top of the test section. The bottom of the melt vessel consists of a $12.7-\mathrm{mm}$ thick stainless steel plate with a $3.175-\mathrm{mm}$ hole at the center. This small opening between the melt vessel and the test section is blocked by a conical stainless-steel plunger. Two thermocouples and a melt stirrer are placed in the melt vessel through openings in the top cover of the melt vessel. Cylindrical radiant heaters surround the melt vessel. For simplicity, this heater, the heaters for the test section and tubing, the thermal insulation, and the thermal control system are not shown in this figure. Since the experiment entails the injection of molten droplets from the melt vessel to the test section, make-up gas must be supplied to the melt vessel. This is accomplished by connecting a compressed nitrogen supply via a pressure regulator and a flow control valve to the top cover of the melt vessel. The connecting tubing is heated and insulated.

The test section has two viewing ports to enable the observation and monitoring of the melt droplets (molten lead doped with a known concentration of mercury) during the experiment. Three thermocouples on the surface of the test section are used to control the test section temperature. A melt receptacle is placed in the bottom of the test section to collect the melt droplets. At the end of the experiment, this receptacle can easily be removed by unbolting the flange at the bottom of the test section. During the experiment hot air at a controlled flow rate and temperature is delivered to the test section bottom via an opening at an elevation just above the melt receptacle. An outlet port for the hot air is provided at the top of the test section.

Any mercury vapor that might be released from the molten droplets within the test section during the experiment will be carried off by the flowing hot air through the test section. In order to detect and extract this mercury from the air stream, the hot air is passed through three condensers and a water pool. All tubing downstream of the point $G$ in Figure 2 is made of glass. As an added precaution, to ensure that no mercury vapor is released to the laboratory environment in the event of an accidental breakage of glass tubing, the entire experimental apparatus resides in a hood.

\subsection{Choice of Experimental Parameters}

Following a 2-year operation, the total mass of all the radioactive isotopes of mercury produced in the lead source rods of the APT-SILC target is calculated [1] to be approximately equal to $20 \mathrm{~kg}$. The total mass of lead in the source rods is equal to $24442 \mathrm{~kg}$. Therefore, the concentration of mercury in the lead after a 2 -year operation would be 0.082 mass $\%$. Since this is very low, higher concentrations of mercury in the molten lead, from 0.2 mass \% to 1.0 mass \%, were used during the experiments to improve the experimental accuracy. Since the vaporization of mercury from molten lead may only increase with increasing concentration of mercury in the lead, the use of higher mercury concentrations is conservative.

As indicated in Section 1.2, the maximum temperature of lead in the pressure tubes during the postulated LBLOCA scenario is calculated to be the melting point of lead $\left(327.4^{\circ} \mathrm{C}\right)$. Therefore, melt temperatures in this neighborhood, from $335^{\circ} \mathrm{C}$ to $346^{\circ} \mathrm{C}$ were used during the experiments. The velocity of hot air in the test section was maintained at a nominal value of $10 \mathrm{~cm} / \mathrm{s}$. 


\subsection{Experimental Procedure}

The experimental procedure is initiated by compiling thin lead strips with a total mass of $1-\mathrm{kg}$. The lead strips are cut from a $99.9 \%$ pure chemical grade lead sheet. A calibrated Sartorius Model 3862 electronic balance is used to measure the total mass of lead strips. The lead strips are then placed in the melt vessel and the test section and the melt vessel are then heated. Hot air is circulated through the test section at a known flow rate and temperature as shown in Figure 2. The target air velocity in the test section is $10 \mathrm{~cm} / \mathrm{s}$. The set points on the temperature controllers are set so that the test section, the melt in the melt vessel, and the hot air injected into the test section are nominally at the same temperature. During this heat-up phase, the bypass valve V1, located upstream of the first condenser, is opened and the valve $\mathrm{V} 2$ is closed so that no hot air flows through the condenser during this phase. The mass of a given quantity (2-g to $10-\mathrm{g}$ ) of mercury in a petri dish is measured by a calibrated Mettler Model H51AR balance. The same balance, which has a standard deviation of $\pm 0.01 \mathrm{mg}$, is also used to measure the initial mass of the empty petri dish and a syringe.

Upon attainment of steady state, the valve V2 is opened and the valve V1 is closed. Then, the pre-measured mass of mercury is injected into the molten pool of lead in the melt vessel by means of a syringe. The stirrer in the melt vessel is used to mix the mercury in the molten pool for a few seconds, and is then locked in position above the melt free surface. The experiment is initiated by moving the plunger and allowing the molten droplets to fall through the test section at a controlled rate. The typical average melt flow rate is $0.8 \mathrm{~g} / \mathrm{s}$ or about 5 drops per second. It is estimated that the flight time of melt droplets through the test section is greater than 0.43 seconds. The molten droplets fall into a melt receptacle at the bottom of the test section. Any mercury released from the molten droplets is carried off by the flowing hot air and would be trapped by the condensers.

At the end of the test, all the electrical heaters are de-energized and the air flow is terminated. After the test apparatus has cooled, the melt receptacle is removed from the test section. In addition, any mercury collected in the condensers would then be weighed. 


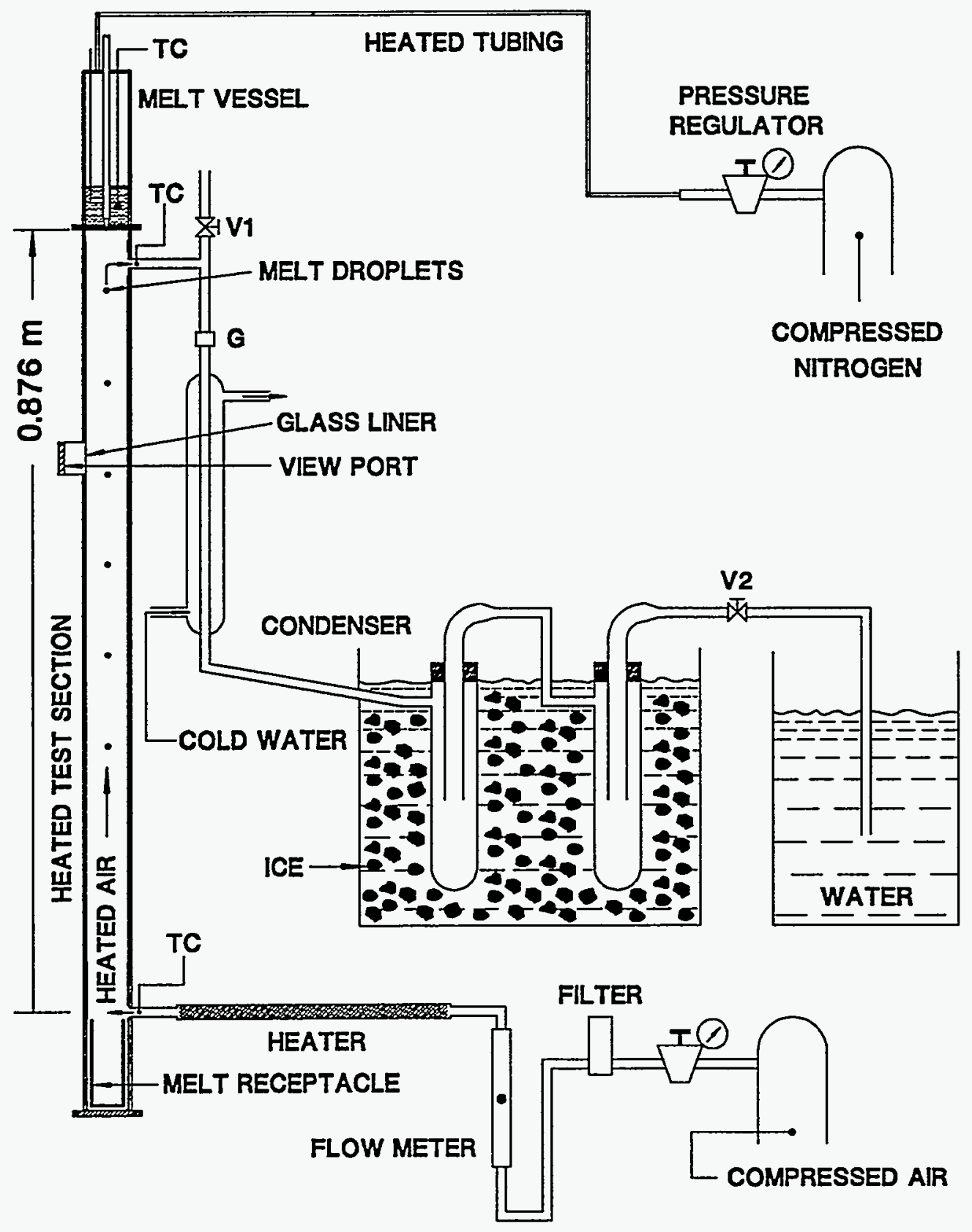

Figure 2. A schematic of the experimental apparatus. 



\section{RESULTS AND DISCUSSION}

The test conditions and the results of the experiments are summarized in Table 1. The second column is the actual mass of mercury injected into the molten lead and the fourth column is the resulting concentration of mercury in the melt. As indicated in the last column of this table, no mercury was observed to be collected in the condensers during any of these tests. The first two "shakedown" experiments are not listed in this table because for these two experiments the bottom portion of the test section adjacent to the melt receptacle was not heated. However, for these experiments as well, no mercury was observed to be released into the condensers.

It is possible that if only a very small fraction of mercury was released from the molten droplets, all of the released mercury could have been deposited on the walls of the test section. Although this is unlikely since the cylindrical walls of the test section consisted of a glass (pyrex) tube, nevertheless, to resolve this uncertainty, measurements of the concentration of mercury by the Inductively Coupled Plasma Atomic Emission Spectrometry (ICP-AES) were made. The following procedure was used for these measurements.

As part of the detailed experimental procedure, at the end of each test the inside walls of the melt vessel are cleaned by removing all the adhering frozen material by means of pliers. In addition, the frozen material collected in the melt receptacle at the bottom of the test section is removed from the melt receptacle. Three samples of solidified frozen material from each of the tests were selected for the chemical analysis. One sample was taken from the frozen material collected from the melt vessel. Analysis of this sample would yield the concentration of mercury in the melt vessel. Since this concentration is known, the analysis of this sample serves as a check on the measurements. This is necessary because low concentrations of mercury are very difficult to measure accurately. The other two samples were selected from the cylindrical slug of frozen material collected from the melt receptacle. One sample was removed from a thin slice about $4 \mathrm{~mm}$ below the top surface, and the second sample was removed from a thin slice about $2 \mathrm{~mm}$ from the bottom surface. The nominal mass of all the samples was $0.5 \mathrm{~g}$.

All of the 18 samples thus obtained for the six tests were dissolved in nitric acid and diluted with distilled water to appropriate concentrations. The resulting sets of solutions were then analyzed ${ }^{1}$ by the ICP-AES to determine the concentrations of mercury in the samples. The measurements are summarized in Table 2. The second column in this table gives the prepared concentration of mercury in the melt held in the melt vessel. This number is obtained directly since the total masses of mercury and lead in the melt are known (see Table 1). For each test, the third and fourth columns are divided into three rows, with one row for each of the three samples as discussed in the above paragraph. The last column gives the concentration of mercury as measured by the ICP-AES for each of the samples.

The difficulties in making very accurate measurements of the concentration of mercury are readily apparent from Table 2. Ideally, the measured $\mathrm{Hg}$ concentration for the samples taken from the melt vessel (given in column 4 and first row for each run) should be the same as the prepared concentration of $\mathrm{Hg}$ in the melt as given in column 2. However, a comparison of these values in Table 2 shows that these numbers can differ by as much as $50 \%$. For example, for Run \# 7, the measured concentration of $\mathrm{Hg}$ from the melt vessel sample is 0.66 mass \%, whereas the initial $\mathrm{Hg}$ concentration in the melt was 0.993 mass \%. Given the uncertainty in the measurements, these results indeed show that the concentration of $\mathrm{Hg}$ in the frozen material collected at the bottom of the test section at the end of the

\footnotetext{
${ }^{1}$ Analysis performed by Dr. Mark Fuhrmann and Ms. Huan Zhou.
} 
experiments is the same as the initial concentration of $\mathrm{Hg}$ in the melt vessel. In other words, it verifies the direct observation that no mercury was released from the molten droplets during any of these experiments. 


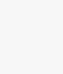

.

\begin{tabular}{|c|c|c|c|c|c|c|c|c|c|}
\hline 0 & $\downarrow 8^{\circ} 0$ & b.OI & $I t \varepsilon$ & $8 \not E$ & $9 \triangleright \varepsilon$ & $\varepsilon I Z^{\circ} 0$ & $I^{\circ} 000 I$ & $\triangleright \varepsilon I^{\circ} \tau$ & 8 \\
\hline 0 & $98^{\circ} 0$ & $\mathcal{E}^{\circ}$ OI & 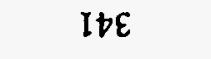 & $t t \varepsilon \varepsilon$ & 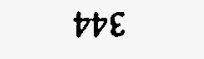 & $\varepsilon 66^{\circ} 0$ & $S^{\circ} 000 \mathrm{I}$ & $6 E 0^{\circ} 0 \mathrm{I}$ & $L$ \\
\hline 0 & $08^{\circ} 0$ & $S^{\circ} 0 I$ & $\mathfrak{I t \varepsilon}$ & $0 \dagger \varepsilon$ & $\varepsilon \not \varepsilon$ & oIt'0 & $I^{\circ} 000 I$ & $9 I I^{\circ} \mathrm{t}$ & 9 \\
\hline 0 & $S L{ }^{\circ} 0$ & $\tau \cdot 0 I$ & SEE & $8 \varepsilon \varepsilon$ & LEE & $I 00^{\circ} I$ & $s^{\circ} 000 \mathrm{I}$ & LII'OI & $S$ \\
\hline 0 & $08^{\circ} 0$ & $\mathcal{E}^{\circ} 0 I$ & SEE & $8 \mathcal{E} E$ & $\operatorname{It} \mathcal{E}$ & ZIt॰0 & $8^{\circ} 000 \mathrm{I}$ & StI't & $t$ \\
\hline 0 & $0 L^{\circ} 0$ & $S^{\prime} 0 I$ & SEE & $8 E \mathcal{E}$ & SEE & $0 z 2^{\circ} 0$ & $\varepsilon^{\cdot 000 I}$ & $60 \tau^{\prime} \tau$ & $\mathcal{E}$ \\
\hline 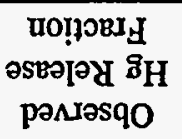 & 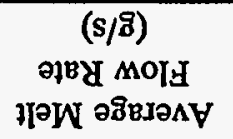 & 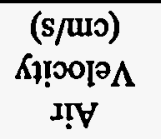 & 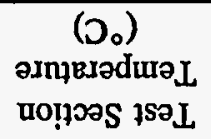 & 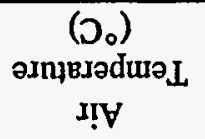 & 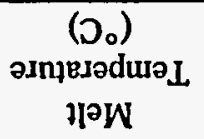 & 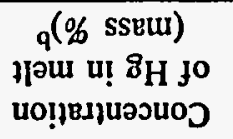 & $\begin{array}{c}\text { (8) } \\
\text { 9d Jo SSEW }\end{array}$ & $\begin{array}{c}\text { (8) } \\
\text { 8H Jo SSEW }\end{array}$ & \# uny \\
\hline
\end{tabular}


Table 2. Mercury concentration measurements in the solidified samples from the Inductively Coupled Plasma Atomic Emission Spectrometry (ICP-AES).

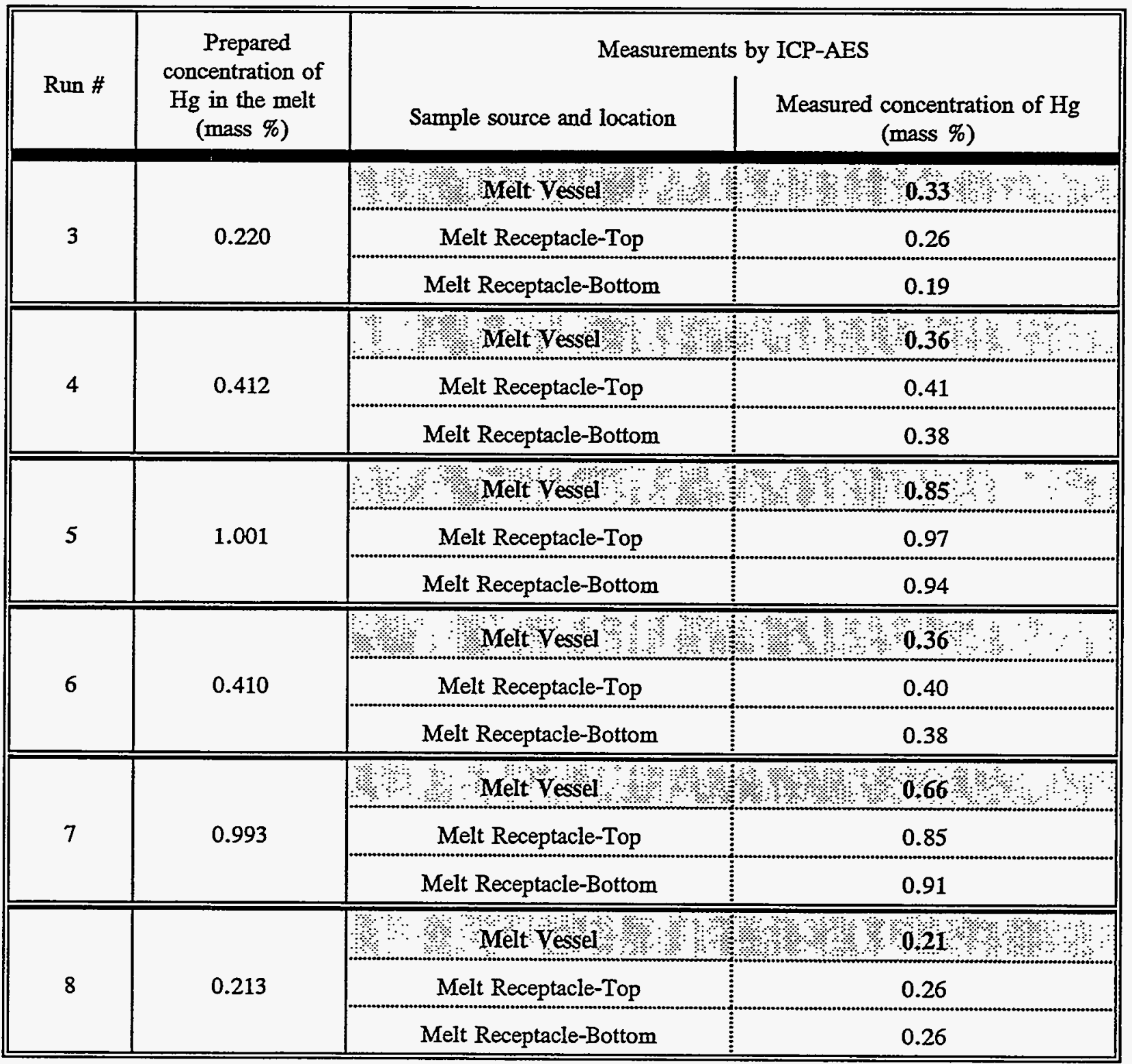




\section{CONCLUDING REMARKS}

For the purpose of quantifying the environmental impact of the proposed APT-SILC facility, experiments were conducted to measure the fraction of mercury inventory released when droplets of molten lead, doped with a known concentration of mercury, fall through a controlled environment. The temperature of molten droplets ranged from $335^{\circ} \mathrm{C}$ to $346^{\circ} \mathrm{C}$, and the concentration of mercury in the droplets ranged from 0.2 mass $\%$ to 1.0 mass \%. By comparison, after a 2-year operation the concentration of mercury in the APT-SILC source rods is calculated to be 0.082 mass \% [1]. In view of the very small concentrations of mercury in the APT-SILC source rods, higher concentrations of mercury were deliberately used for the experiments to improve the reliability of measurements.

Direct observation of the condensers, which are designed to trap any released mercury during the experiments, showed no mercury to be present at the end of every test. Chemical analysis of the solidified material collected at the bottom of the test section by the Inductively Coupled Plasma Atomic Emission Spectrometry confirmed the conclusion that no mercury was released from molten droplets during the experiments. Since the concentration of mercury in the droplets during the experiments was larger than that for the APT-SILC target, and since the vaporization of mercury from molten lead may only increase with increasing concentration of mercury, the experimental results are conservative and it can safely be concluded that no mercury would be released from the APT-SILC source rods that melt during a postulated conservative LBLOCA scenario.

In view of the uncertainties in the measurement of mercury concentrations by the ICP-AES, it could be argued that if only a very small fraction of mercury were released from the molten droplets during the experiments, all of the released mercury could have deposited on the walls of the test section upstream of the condensers. However, it should be noted that the walls of the test section were nominally at the same temperature as the melt and the hot air during the experiments, whereas during the postulated accident in the APT-SILC source, the walls of the pressure tubes, the top header, and the outlet piping would be much colder $\left(\approx 100^{\circ} \mathrm{C}\right)$ than the melt temperature or the steam $\left(\mathrm{D}_{2} \mathrm{O}\right)$ temperature. Thus the extent of mercury deposition on these walls of the APT source (assuming if any mercury was released from the molten source rod material) is likely to be much greater than that likely to have occurred during these experiments. In addition, visual observations of the glass liner at the end of experiments did not show any evidence of mercury deposition. Therefore, it is reasonable to conclude that no mercury vapor is likely to be released from the molten source rod material to the confinement atmosphere during a postulated conservative LBLOCA accident scenario discussed in Section 1.1. 


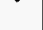




\section{REFERENCES}

1. Van Tuyle, et al., "Topical Report on a Preconceptual Design for the Spallation Induced Lithium Conversion (SILC) Target fort he Accelerator Production of Tritium (APT), "BNL-52401, UC731, ATD/APT93-0025 (REV.0), Brookhaven National Laboratory Report, September 1993. 